\title{
Effect of Micro-particles in Iron Ore on the Granule Growth and Strength
}

\author{
Shinji KAWACHII) and Shunji KASAMA ${ }^{21}$ \\ 1) Environmental \& Process Technology Center, Nippon Steel Corp., 20-1 Shintomi Futtsu Chiba, $293-8511$ Japan. \\ 2) Oita Works, Nippon Steel Corp., Oaza Nishinosu 1, Oita City, Oita, 870-0992 Japan.
}

(Received on February 16, 2011; accepted on April 22, 2011)

\begin{abstract}
Pelletization tests were conducted using pulverized iron ore to record changes in pellet strength by changing the volume of micro-particles and ore types. The strength of pellets when completely dried can be explained by the volume of micro-particles in ore, and the greater the volume of micro-particles, the higher the strength of pellets. The rate of increase in pellet strength by micro-particles when completely dried varies depending on the ore type of micro-particles and the strength increases in the order of pisolite, Marramamba, and hematite. Regarding the generation of pellet strength during the moisture drying process, there are two different mechanisms at work at the early stage and the last stage before complete dryness. The rise in strength at the early stage of drying is considered attributable to the increase in liquid viscosity due to the condensation of micro-particles and APD in the liquid, and the increase in strength just before complete dryness is considered attributable to the formation of solid bridges caused by the movement and rearrangement of micro-particles.
\end{abstract}

KEY WORDS: agglomeration; iron ore sintering; granulation; moisture; micro-particle; anionic-polymerdispersant; drying process; granule strength.

\section{Introduction}

Sinter is agglomerate made of fine iron ore that is cheaper than pellets and lump iron ore and is superior in terms of reducibility and dropping characteristics. For the two reasons of better production cost performance and stable operation of blast furnaces, sinter has been used in Japan as one of the main sources for blast furnace operation.

In order to satisfy the need to improve the productivity of sinter, a broad range of research and development efforts have been made from the viewpoints of the technology to pre-treat fine iron ore and the technology to control the charging structure on the entire spread of the sintering bed. As for the pre-treatment technology, technologies already developed and in actual application are selective granulation technology that partially granulates high-alumina iron ore, ${ }^{1)}$ coke breeze, and limestone coating granulation, ${ }^{2)}$ dispersant binder technology that utilizes submicron particles effectively, ${ }^{3)}$ and others. Where the technology to control the charging structure is concerned, there is charging technology to appropriately segregate sinter materials, ${ }^{4)}$ technology to suppress the contraction of the sinter bed during sintering, ${ }^{5)}$ technology to form ventilation pores in the sintering zone, ${ }^{6}$ ) and others, and each of them is contributing greatly to the improvement of productivity of sintering machines in operation.

Recently in the research project on "Sintering through Designing of Composite Granulation \& Bed Structure" undertaken by a group led by Kasai, MEBIOS (mosaic embedding iron ore sintering $)^{7-9)}$ is under study. The main objectives of the MEBIOS sintering method are to find measures for the effective utilization of Marramamba iron ore and measures to improve sinter productivity, and by embedding pellets made mainly of Marramamba iron ore, ventilation routes are effectively formed in the sintering structure, improving the productivity of sinter. To realize this MEBIOS method, a granulation technology for producing solid pellets that do not break during transportation and on the sintering bed is sought.

$\mathrm{We}^{10)}$ conducted iron ore granulation tests using anionic polymer dispersant (hereinafter abbreviated to APD) and reported that the addition of APD increases micro-particles in granulation moisture, improving granulation. This improvement in granulation is also maintained with the dried granulated product, suggesting that the effective utilization of micro-particles using APD would produce very strong granules.

In this report, in order to clarify the mechanism whereby the use of micro-particles improves granulation, pelletization tests were conducted using pulverized iron ore to record changes in pellet strength by changing the amount of microparticles and ore types. Furthermore, in order to clarify the mechanism of producing strength when dried, a characteristic of APD, changes in the strength of pellets in the drying process were investigated to examine the behavior of microparticles.

\section{Experiment Procedure}

In order to clarify the influence of micro-particles on the 
strength of granulated iron ore, two pelletizing tests were conducted. One was to measure changes in pellet strength that take place due to changes in the amount and types of micro-particles, and the other was to measure changes in pellet strength as the pellets dried. For these tests, to evaluate the bond strength of the adhered zone in the iron ore granules, pellets having no core particles were prepared and a uniaxial compression strength tester was used.

\subsection{Specimens}

The types of iron ore used for the tests are shown in Table 1. Ores $A$ to $C$ are Australian iron ore; ore $A$ is alumina pisolite iron ore, ore $\mathrm{B}$ is low-alumina pisolite iron ore, and ore $\mathrm{C}$ is Marramamba iron ore. Ore $\mathrm{D}$ is Brazilian hematite pellet feed. As for the source of $\mathrm{MgO}$, serpentine is mixed was also conducted, as a blend for pellets with improved reaction of the melting zone.

Ores A, C, and D were completely dried and sieved to achieve fine particles of smaller than $0.25 \mathrm{~mm}$, and then the fine particles were pulverized to be smaller than $10 \mu \mathrm{m}$ using a fluidized bed opposite jet mill. Furthermore, in order to achieve pulverized fine particles with different size distribution, for ore $\mathrm{C}$, specimens were also prepared by pulverizing for thirty minutes using a planetary ball mill. The particle size distribution of each specimen after adjustment of its particle size and amount of micro-particles to smaller than $10 \mu \mathrm{m}$ are shown in Table 2. Particle size distribution was measured using a laser light diffraction particle size analyzer, and the amount of micro-particles was measured by the Andreasen pipette method ${ }^{10)}$ referred to in the last report. The Andreasen pipette method is a measuring method that exploits differences in sedimentation speed depend-

Table 1. Chemical composition of sample ores.

\begin{tabular}{cccccc} 
& & & & & $($ mass\%) \\
\hline Ore A & 56.8 & 2.75 & 6.01 & 0.21 & 7.80 \\
Ore B & 58.2 & 1.45 & 5.11 & 0.06 & 9.31 \\
Ore C & 61.2 & 2.35 & 3.50 & 0.10 & 5.80 \\
Ore D & 68.17 & 0.42 & 1.09 & 0.10 & 0.53 \\
Serpentine & 5.21 & 2.12 & 53.26 & 34.18 & 12.61 \\
\hline
\end{tabular}

Table 2. Size distribution of iron ores for granulation test.

\begin{tabular}{rcrrrrr}
\hline Ore & $\begin{array}{c}\text { Pulvarized } \\
\text { method }\end{array}$ & $\begin{array}{c}250- \\
100 \mu \mathrm{m}\end{array}$ & $\begin{array}{r}100- \\
10 \mu \mathrm{m}\end{array}$ & $\begin{array}{r}10- \\
1 \mu \mathrm{m}\end{array}$ & $-1 \mu \mathrm{m}$ & $\begin{array}{c}\text { Micro- } \\
\text { particle }\end{array}$ \\
\hline A & No pulvarization & 25.4 & 31.8 & 22.0 & 20.8 & 19.8 \\
A & Jet Mill & 0.0 & 0.0 & 92.8 & 7.2 & 96.7 \\
B & No pulvarization & 25.6 & 33.1 & 21.4 & 19.9 & 18.6 \\
C & No pulvarization & 18.5 & 26.9 & 22.4 & 32.2 & 20.9 \\
C & Ball mill & 8.9 & 24.3 & 32.5 & 34.3 & 37.3 \\
C & Jet Mill & 0.0 & 1.4 & 70.7 & 28.9 & 89.1 \\
D & No pulvarization & 11.9 & 88.1 & 0.0 & 0.0 & 2.2 \\
D & Jet Mill & 0.0 & 0.0 & 100.0 & 0.0 & 99.8 \\
SP & No pulvarization & 47.6 & 52.4 & 4.8 & 5.2 & 8.2 \\
\hline
\end{tabular}

SP; Serpentine ing on particle diameter, and for the current measurement, suspension at $200 \mathrm{~mm}$ deep after a lapse of 20 minutes since the start of sedimentation was performed to calculate the amount of micro-particles. Assuming that the density of micro-particles was $4000 \mathrm{~kg} / \mathrm{m}^{3}$, the upper-limit diameter of micro-particles sampled at this time was $10 \mu \mathrm{m}$.

\subsection{Granulation Evaluation Tests of Micro-particle Blended Pellets}

In order to investigate the influence of the amount of micro-particles on the granulation of pellets and on their strength, a pellet feed with lower granulation performance, which was ore $\mathrm{D}$, and various pulverized iron ore types were blended to produce pellets.

The blending levels of the specimens are shown in Table 3. Iron ore D and pulverized iron ores A, C, or D are blended with a mass $\%$ of 10 to 40 . For comparison, for No. 14 , No. 15 , and No. 16, a level of blending non-pulverized ore A or $\mathrm{C}$ to smaller than $0.25 \mathrm{~mm}$ was set up. Where the microparticles in Table 3 are concerned, the values obtained by averaging the micro-particles measured for individual brands of ore with their blending ratios are shown.

The test flow is illustrated in Fig. 1. Three kg of a blended specimen was blended for one minute with an kneading machine, and then with water and APD added, it was kneaded for four minutes. The specimen thus kneaded was then granulated for four minutes in a drum mixer with an inner diameter of $1000 \mathrm{~mm} \phi$. The amount of APD added was a constant of 0.5 mass $\%$ as converted to weight of ore solid, and the water added varied from 7 to 15 mass $\%$. In order to evaluate the granulation yield of adjusted pellets, the produced $600 \mathrm{~g}$ pellets were dried up to 3.0 mass $\%$ moisture and the $+5 \mathrm{~mm}$ yield was measured with a hand sieve. Then, to evaluate the strength of the pellets, 20 pellets of 4.75 to $6.3 \mathrm{~mm}$ in diameter were selected and the compres-

Table 3. Blending ratio for micro-particle adding granulation test.

\begin{tabular}{|c|c|c|c|c|c|}
\hline \multirow{2}{*}{ No. } & \multicolumn{3}{|c|}{ Source of micro-particle } & \multirow{2}{*}{$\begin{array}{c}\text { Ore D } \\
(\operatorname{mass} \%)\end{array}$} & \multirow{2}{*}{$\begin{array}{c}\text { Micro-particle } \\
(\text { mass } \%)\end{array}$} \\
\hline & Ore & Pulverization & $(\operatorname{mass} \%)$ & & \\
\hline 1 & A & Jet mill & 10 & 90 & 11.6 \\
\hline 2 & A & Jet mill & 20 & 80 & 21.1 \\
\hline 3 & A & Jet mill & 25 & 75 & 25.8 \\
\hline 4 & $\mathrm{C}$ & Jet mill & 20 & 80 & 19.5 \\
\hline 5 & $\mathrm{C}$ & Jet mill & 25 & 75 & 23.9 \\
\hline 6 & $\mathrm{C}$ & Jet mill & 30 & 70 & 28.2 \\
\hline 7 & $\mathrm{D}$ & Jet mill & 10 & 90 & 11.3 \\
\hline 8 & $\mathrm{D}$ & Jet mill & 20 & 80 & 20.5 \\
\hline 9 & $\mathrm{D}$ & Jet mill & 25 & 75 & 25.1 \\
\hline 10 & $\mathrm{D}$ & Jet mill & 30 & 70 & 29.7 \\
\hline 11 & $\mathrm{C}$ & Ball Mill & 20 & 80 & 8.7 \\
\hline 12 & $\mathrm{C}$ & Ball Mill & 40 & 60 & 15.9 \\
\hline 13 & $\mathrm{C}$ & Ball Mill & 60 & 40 & 23.0 \\
\hline 14 & A & No Pulverization & 40 & 60 & 8.9 \\
\hline 15 & A & No Pulverization & 60 & 40 & 12.5 \\
\hline 16 & $\mathrm{C}$ & No Pulverization & 60 & 40 & 12.5 \\
\hline
\end{tabular}




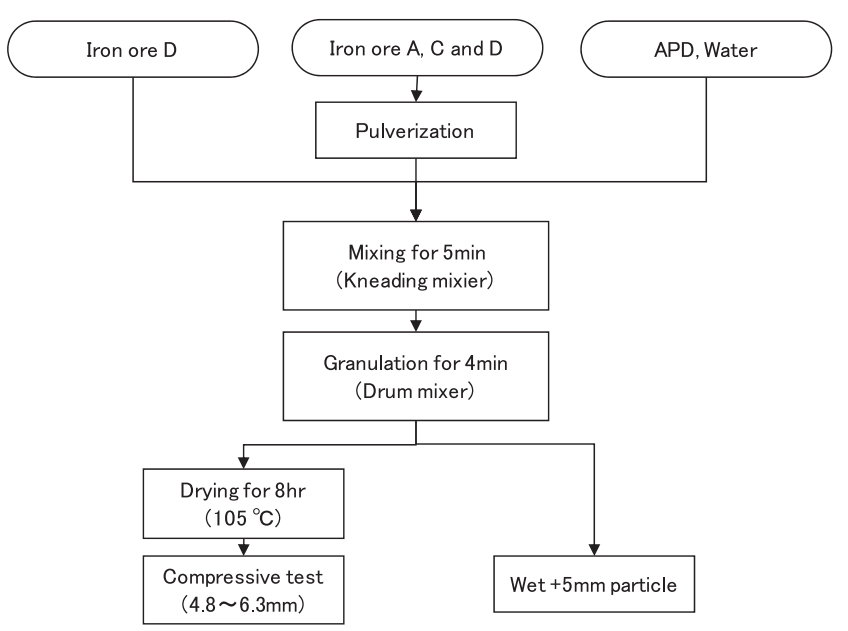

Fig. 1. Method of granulation test for micro-particle adding pellet.

sive strength was measured when they were completely dried. The fracture faces of the pellets after the compressive strength testing were observed using a scanning electron microscope (hereinafter abbreviated to SEM), and the distribution of micro-particles inside the pellets was directly examined.

\subsection{Pellet Strength Evaluation Testing during the Dry- ing Process}

By changing the drying time of the pellets, and therefore changing the residual moisture in the pellets, the relationship between the residual moisture in the pellets and the strength of the pellets was investigated. The variations in the mix of raw materials are given in Table 4. Here, three kinds of blending were set up, assuming the use of pellets using the MEBIOS method. For the amount of micro-particles, the values of the weighted averages of individual brands were used as shown in Table 3.

The testing flow is illustrated in Fig. 2. The blended specimens were mixed for one minute each with a shearing mixer, then water and 0.2 mass $\%$ APD were added, and the specimens were kneaded for a further two minutes. The specimens thus kneaded were then granulated for four minutes in a drum mixer with an inner diameter of $1000 \mathrm{~mm} \phi$. Two hundred $\mathrm{kg}$ of the pellets produced were arranged in a single layer on a sieve with a screen mesh of $0.25 \mathrm{~mm}$ and dried at a temperature of $105^{\circ} \mathrm{C}$. The drying time was changed from zero to 30 minutes, the residual moisture in the pellets was adjusted, and then 20 pellets of 4.75 to $6.3 \mathrm{~mm}$ in size were selected and their compressive strength measured. Furthermore, the residual moisture in the specimens after the strength measurement was also measured.

\subsection{Observation of the Behavior of Micro-particles during the Drying Process}

In order to check the behavior of micro-particles in suspension during the drying process, observation was made using a transmission digital microscope. A pattern diagram of the tests is shown in Fig. 3. A suspension of 1 mass $\%$ jetmilled pulverized iron ore $\mathrm{C}$ was prepared and $50 \mu \mathrm{L}$ of it was dropped onto a glass plate and spread thinly to $5 \mathrm{~mm} \phi$. By heating this suspension using a halogen lamp, the behavior of micro-particles in the drying process was observed using a transmission digital microscope. In order to check
Table 4. Blending ratio for semi-dry-pellet granulation test.

\begin{tabular}{cccccc}
\hline No. & OreB & OreC & OreD & Serpentine & Micro-particle \\
\hline 17 & - & 48.8 & 45.1 & 6.1 & 12.9 \\
18 & 21.6 & 48.8 & 23.5 & 6.1 & 16.1 \\
19 & - & 62.3 & 29.9 & 7.8 & 15.0 \\
\hline
\end{tabular}

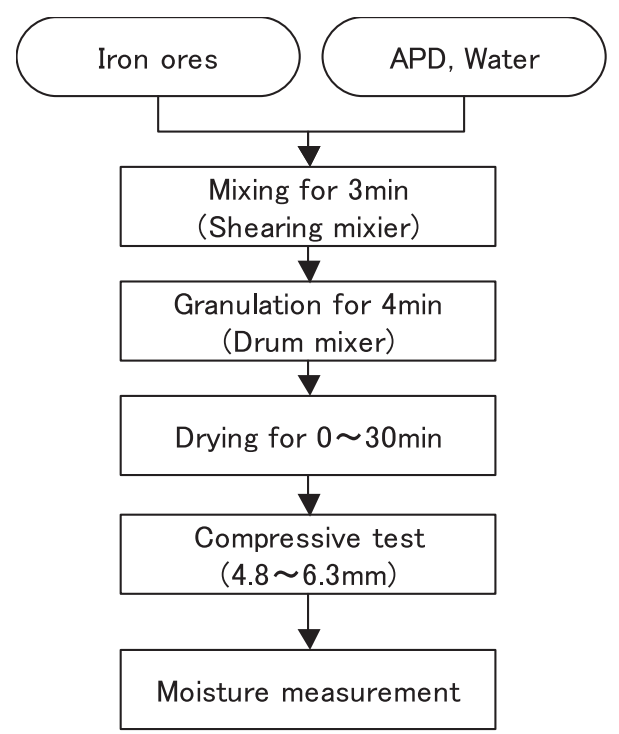

Fig. 2. Method of granulation test for drying process changing pellet.

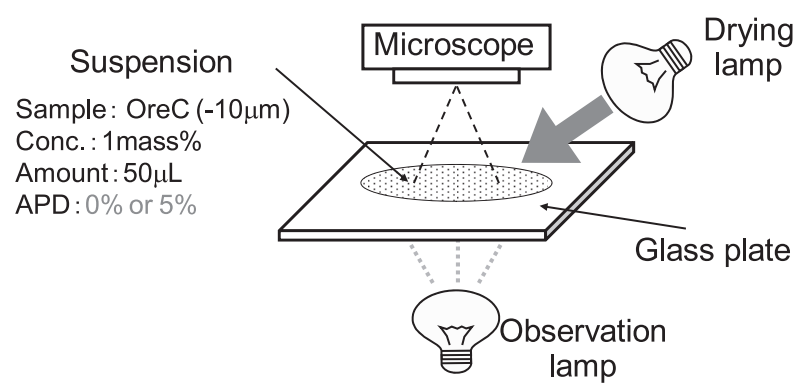

Fig. 3. Schematic of observation method for migration phenomena of micro-particle in drying process.

the influence of APD on the behavior of micro-particles, an observational comparison of two levels was made, one where APD was not added to the suspension, and the other to which was added 5 mass $\%$ APD in the standard of solid iron ore.

\section{Results}

\subsection{Influence of Micro-particles in the Growth of Granules}

The results of all granulation tests are shown on Table 5. In Table 5, " $X$ " represents the condition where the yield of $+5 \mathrm{~mm}$ was less than 10 mass $\%$, " $\bigcirc$ " represents the condition where the yield of $+5 \mathrm{~mm}$ was more than $10 \mathrm{mass} \%$ and normal pellets could be recovered, and " $\triangle$ " represents the condition where the specimen became slurry due to excessive moisture. Furthermore, the conditions in Table 5 where the compressive strength was not measured mean that the 
Table 5. Test results of micro-particle adding granulation test.

\begin{tabular}{|c|c|c|c|c|c|}
\hline No. & $\begin{array}{l}\text { Micro-particle } \\
\quad(\operatorname{mass} \%)\end{array}$ & $\begin{array}{l}\text { Moisture } \\
\text { (mass\%) }\end{array}$ & $\begin{array}{l}\text { Granule } \\
\text { condition }\end{array}$ & $\begin{array}{c}\text { Wet } \\
+5 \mathrm{~mm} \\
(\mathrm{mass} \%)\end{array}$ & $\begin{array}{c}\text { Compressive } \\
\text { Strength } \\
(\mathrm{MPa})\end{array}$ \\
\hline 1 & 11.6 & 11.0 & $\bigcirc$ & 92.2 & 0.83 \\
\hline 2 & 21.1 & 9.5 & $\bigcirc$ & 93.4 & 1.74 \\
\hline \multirow[t]{2}{*}{3} & 25.8 & 8.5 & $\times$ & 9.2 & - \\
\hline & 25.8 & 9.0 & 0 & 40.3 & 1.74 \\
\hline 4 & 19.5 & 9.0 & 0 & 60.6 & 1.28 \\
\hline 5 & 23.9 & 8.0 & 0 & 88.7 & 1.58 \\
\hline 6 & 28.2 & 7.5 & 0 & 49.7 & 1.73 \\
\hline \multirow[t]{2}{*}{7} & 11.3 & 9.0 & $\times$ & 0.2 & - \\
\hline & 11.3 & 10.0 & $\bigcirc$ & 10.8 & 0.33 \\
\hline 8 & 20.5 & 8.5 & $\bigcirc$ & 12.5 & 0.47 \\
\hline \multirow[t]{2}{*}{9} & 25.1 & 7.0 & $\bigcirc$ & 6.8 & 0.39 \\
\hline & 25.1 & 8.0 & $\triangle$ & 82.1 & - \\
\hline 10 & 29.7 & 7.5 & 0 & 49.7 & 1.25 \\
\hline \multirow[t]{4}{*}{11} & 8.7 & 11.0 & $\times$ & 5.6 & - \\
\hline & 8.7 & 12.0 & $\bigcirc$ & 25.1 & 0.28 \\
\hline & 8.7 & 13.0 & $\bigcirc$ & 36.6 & 0.20 \\
\hline & 8.7 & 14.0 & $\triangle$ & 81.9 & - \\
\hline \multirow[t]{4}{*}{12} & 15.9 & 9.0 & $\times$ & 2.8 & - \\
\hline & 15.9 & 10.0 & 0 & 35.7 & 0.94 \\
\hline & 15.9 & 10.5 & $\bigcirc$ & 70.4 & 0.88 \\
\hline & 15.9 & 11.0 & $\triangle$ & 83.5 & - \\
\hline \multirow[t]{4}{*}{13} & 23.0 & 8.0 & $\times$ & 5.8 & - \\
\hline & 23.0 & 9.0 & $\bigcirc$ & 79.2 & 1.47 \\
\hline & 23.0 & 10.0 & $\triangle$ & 85.6 & - \\
\hline & 23.0 & 12.0 & $\triangle$ & 94.6 & - \\
\hline 14 & 8.9 & 13.0 & $\bigcirc$ & 68.1 & 0.86 \\
\hline \multirow[t]{3}{*}{15} & 12.5 & 12.0 & $\times$ & 6.8 & - \\
\hline & 12.5 & 13.0 & $\bigcirc$ & 48.1 & 1.14 \\
\hline & 12.5 & 14.0 & $\bigcirc$ & 76.0 & 0.91 \\
\hline \multirow[t]{2}{*}{16} & 12.5 & 12.0 & $\bigcirc$ & 25.5 & 0.78 \\
\hline & 12.5 & 13.0 & 0 & 78.8 & 0.55 \\
\hline
\end{tabular}

necessary number of pellets of 4.75 to $6.3 \mathrm{~mm}$ in diameter could not have been obtained. The relationship between micro-particles and granulation moisture is shown in Fig. 4. It shows that the range in which pellets form is narrower than expected, and exists adjacent to the powder zone below and the slurry zone above, and a negative correlation between the correct moisture and the amount of microparticles is observed, i.e., the correct moisture for granulation can be reduced as the amount of micro-particles increases, irrespective of blending.

\subsection{Influence of Micro-particles on the Strength of Pel- lets}

As an example that shows the difference in pellet strength depending on the pulverization strength, the relationship between the blending amount of iron ore $\mathrm{C}$ and pellet compressive strength is shown in Fig. 5, which shows that there

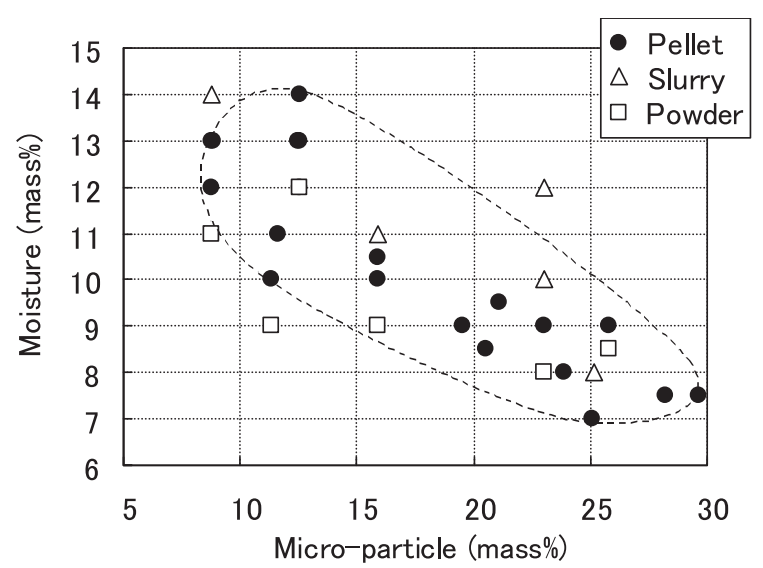

Fig. 4. Relation between moisture and micro-particle.

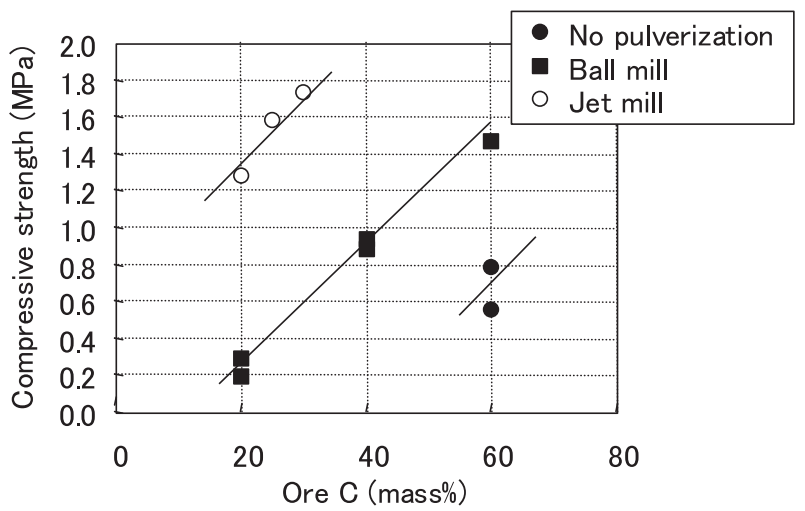

Fig. 5. Relation between compressive strength and ore $C$ in the case of ore $\mathrm{C}$ and Ore D granulation.

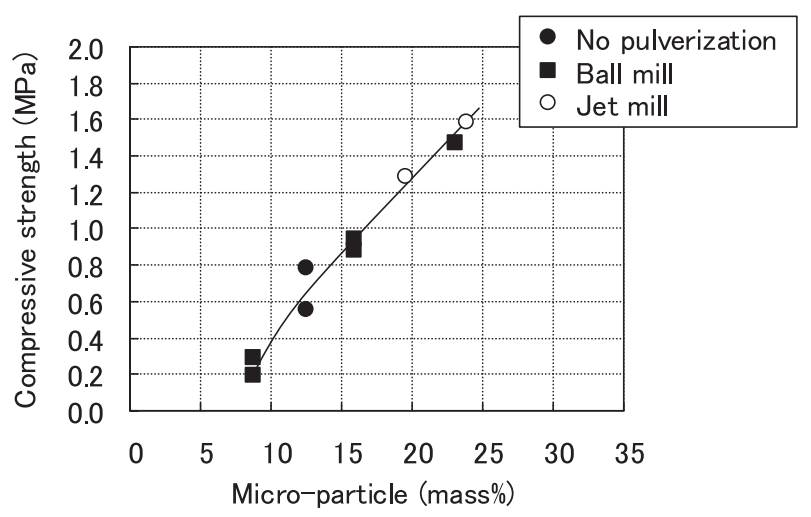

Fig. 6. Relation between compressive strength and micro-particle in the case of ore $\mathrm{C}$ and Ore D granulation.

is a trend where the higher the blend amount of iron ore $\mathrm{C}$, the stronger the pellet. When comparing the difference in the method of pulverization, it was confirmed that even if the blend amount of iron ore $\mathrm{C}$ is more or less the same, the higher the pulverization rate, the higher the compressive strength.

The data in Fig. 5 are rearranged regarding the relationship between the amount of micro-particles and the compressive strength. The result is shown in Fig. 6, which shows that irrespective of the blend amount of iron ore $\mathrm{C}$ and the pulverization method, the compressive strength of pellets is primarily in the order of the amount of microparticles and there is a positive correlation between the 
amount of micro-particles and the compressive strength, i.e., the higher the amount of micro-particles, the greater the compressive strength. In other words, for strength in iron ore granules, the micro-particles in raw materials can be considered to be the governing factor.

The relationship between the amount of micro-particles and the compressive strength as a result of all granulation tests is shown in Fig. 7. Irrespective of the blending of micro-particles of whichever iron ore, the relationship between the micro-particle amount and the compressive strength showed a positive correlation. However, the degree of influence is different depending on the iron ore blended, and when compared based on the same amount of microparticles, the strength was in descending order of iron ore A that is pisolite iron ore, iron ore $\mathrm{C}$ that is Marramamba iron ore, and iron ore $\mathrm{D}$ that is hematite iron ore. This order corresponds with amount of gangue or ore density. The effect of gangue and density is subject of further investigations.

\subsection{Result of the Observation with SEM of the Frac- ture Faces of Pellets}

As a representative example, SEM observations were made of pellet fracture faces for three conditions: No. 16, 60 mass \% blend of Marramamba iron ore $\mathrm{C}$ without pulverization, No. 5, 25 mass \% blend of jet-milled pulverized ore, and No. 9, 25 mass\% blend of jet-milled pulverized ore of hematite iron ore D. The results are shown in Fig. 8. The fracture faces of No. 16 that had medium strength showed a stonewall-looking structure of aggregated iron ore particles comparatively large in size, and there were large voids between particles. On the other hand, as for the fracture fac-

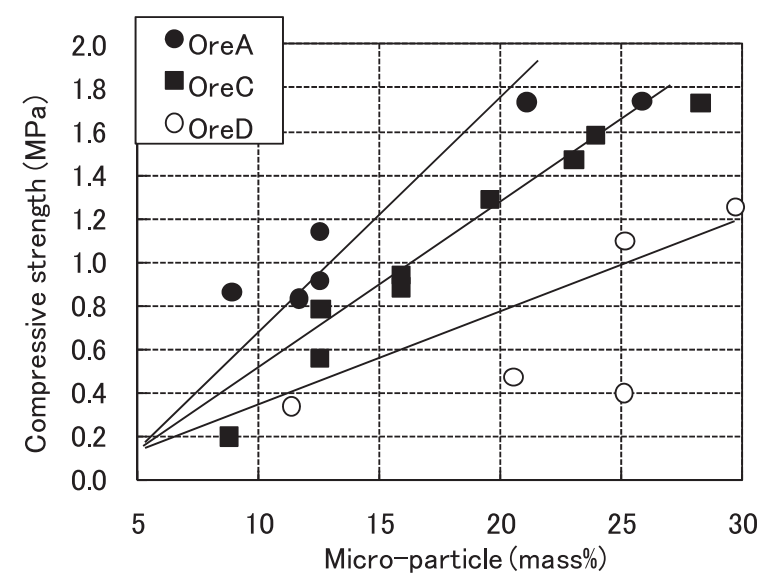

Fig. 7. Relation between compressive strength and micro-particle. es of No. 5 pellets that were the strongest, the voids between iron ore particles were thickly filled in as if plastered with the mortar of micro-particles. The fracture faces of No. 9 pellets that were low in strength had the same structure as No. 5 filled in by micro-particles, but compared with the fracture faces of pellets blended with iron ore $\mathrm{C}$, the fracture faces of pellets with iron ore D blend were coarse and the voids were filled in by comparatively large micro-particles. The above results indicate that to raise the compressive strength, it is effective to fill in the voids between particles with micro-particles.

\subsection{Change in Pellet Strength Due to Drying}

The relationship between the residual moisture and the compressive strength from pellet drying tests is shown in Fig. 9. Irrespective of the blending condition, the compressive strength and the residual moisture showed a certain constant relationship. All pellets showed a low strength of around $0.2 \mathrm{MPa}$ immediately after granulation, but a trend was confirmed whereby the strength increased as the residual moisture decreased. There are no effects of micro-particle in this moisture range. The compressive strength showed a rather slow rising curve during the drying process of 11 mass $\%$ to 2 mass $\%$. However, it showed a sudden steep rise during the drying process nearing complete dryness of 2 mass $\%$ to 0 mass $\%$ and the plots are separated by effect of micro-particle. As such, the rising curve of strength associated with the drying process is characterized by a slow rise at the early stage of drying, changing suddenly to a steep rise at the end of the drying process, indicating that there are different strength-generating mechanisms at work. The former mechanism is due to moisture and the latter is due to micro-particle.

\subsection{Behavior of Micro-particles in Suspension during the Drying Process}

The result of the transmission microscopic observation of the behavior of micro-particles in suspension during the drying process is shown in Fig. 10. Under the condition where 5 mass\% APD was added, it was observed that particles of hematite were in a long, thin cluster form of 50 to $100 \mu \mathrm{m}$, and that between the clusters, goethite particles exist independently. Also observed was the drifting in Brownian motion in the water of submicron particles inferred to be clay or goethite particles. At the early stage of drying, only the submicron particles were convected by liquid, and in time, the goethite particles also started moving. At the stage

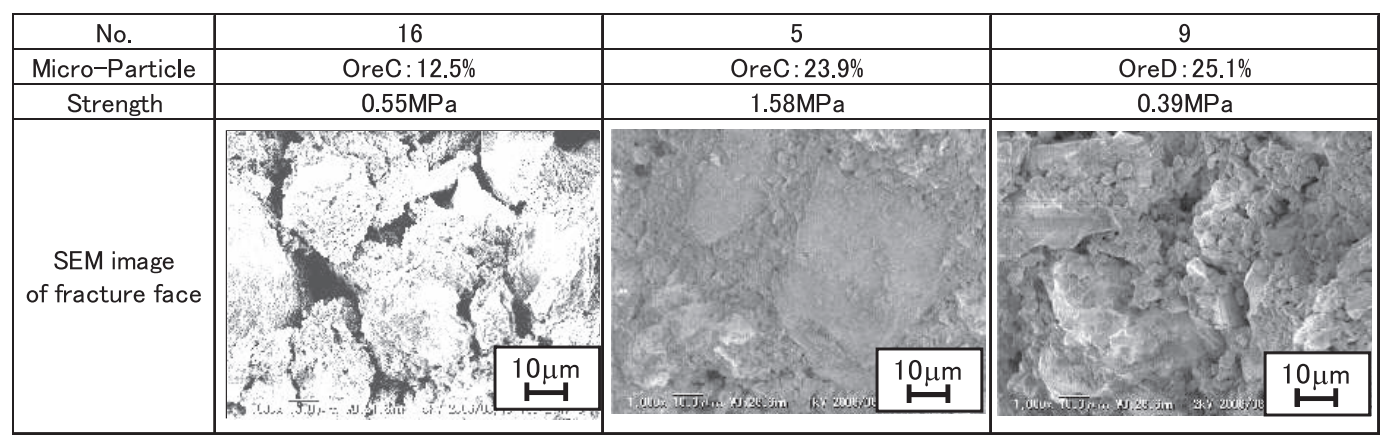

Fig. 8. SEM image of fracture face of iron ore pellet. 


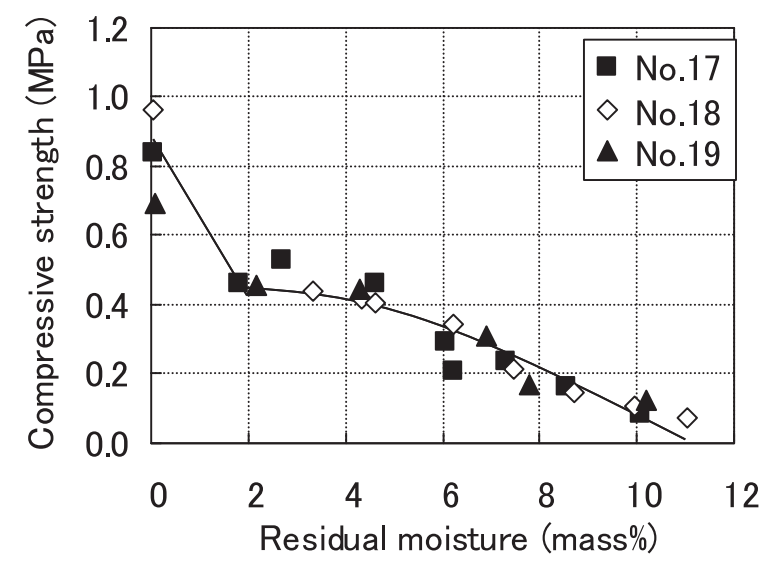

Fig. 9. Relation between compressive strength and residual moisture.

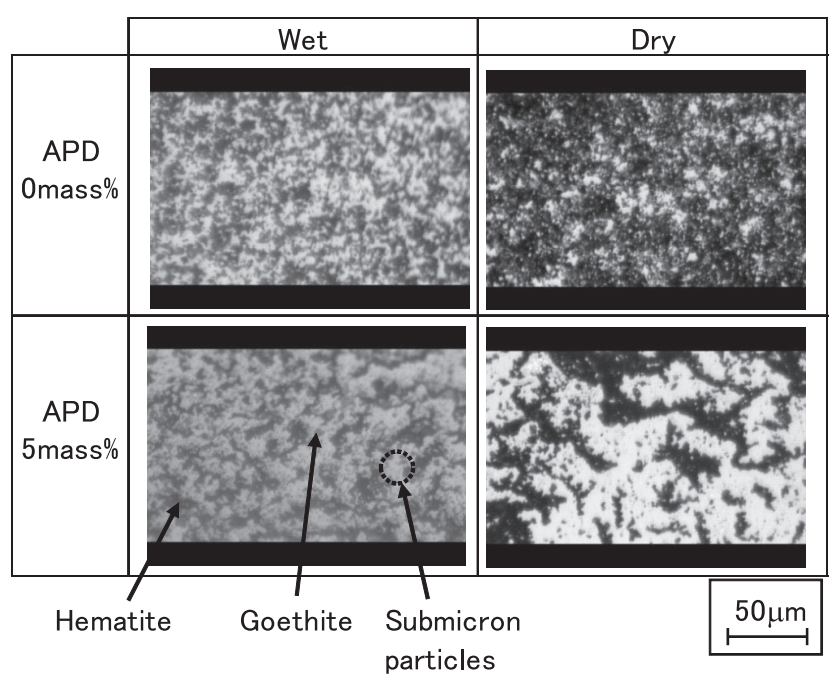

Fig. 10. Observation result of suspension by transmission microscope.

immediately prior to complete dryness, the hematite particles also moved, finally forming several large aggregates by their rearrangement. On the other hand, under the condition where APD is not added, hematite particles formed aggregates that took in goethite particles, and almost no floating of submicron particles in the water was observed. Even after the start of drying, no large movement of particles was observed, and at the time of complete dryness, they solidified where they were.

As a result of the above observation, APD plays the role of not only prompting the dispersing movement of submicron micro-particles as its proper function of dispersant, but also enabling the rearrangement of comparatively large particles during the final drying process.

\section{Discussion}

\subsection{Mechanism of Promoting Growth of Granules by Micro-particles}

As examples indicating changes in granulation of pellets due to moisture, the relationship between granulation moisture and the yield of $+5 \mathrm{~mm}$ pellets in No. 11, No. 12, No. 13, and No. 15 is shown in Fig. 11. It is shown, irrespective of blending, that a yield of $+5 \mathrm{~mm}$ pellets does not increase

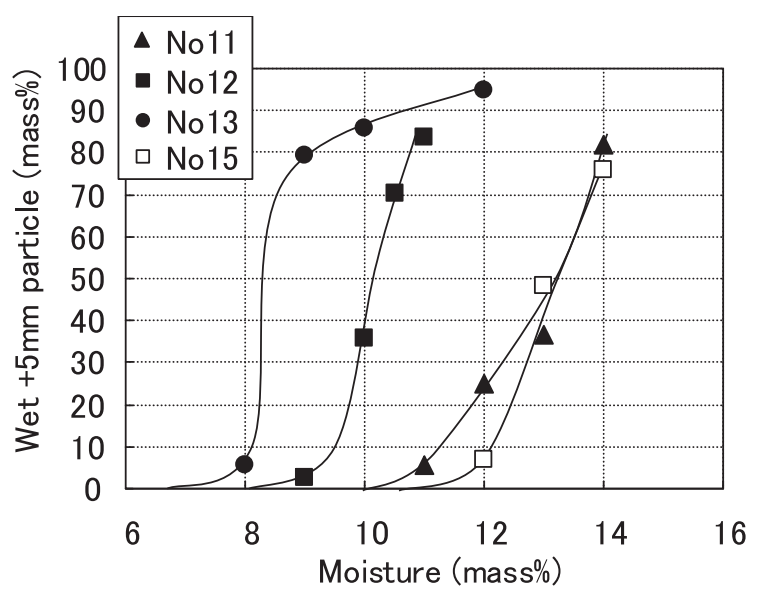

Fig. 11. Relation between wet $+5 \mathrm{~mm}$ particle and moisture in the case of ore $\mathrm{C}$ and ore $\mathrm{D}$ granulation.

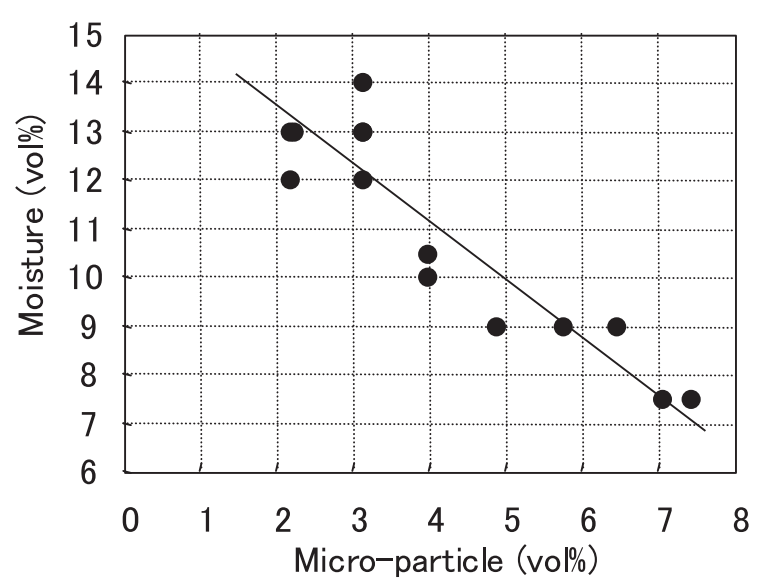

Fig. 12. Relation between volumes of moisture and volumes of micro-particle.

linearly to the granulation moisture, and below a certain moisture level, it increases rapidly and approaches 100 mass\%, showing a change in sigmoidal type. In the field of powder technology, to evaluate moist powder, an index of saturation degree $^{11)}$ is used. The saturation degree represents the ratio of moisture amount in the amount of voids in powder under granulation, and in the state where moisture fills up all the voids, the saturation degree is 1.0. Sekiguchi et al. ${ }^{11)}$ conducted granulation tests on Marramamba iron ore using a tapping-type gyratory granulator and reported that for the formation of pellets, the saturation degree needs to be higher than 0.92 , and when the saturation degree exceeds 1.02 , it becomes slurry. The change in yield shown in Fig. 11 and the result of analysis of the pellet formation range in Fig. 4 are indicative of similar phenomena to the granulation phenomena explained by Sekiguchi et al.

The relationship between the ratio of granulation moisture volume and the ratio of micro-particle volume within the pellet formation range is shown in Fig. 12. For this purpose, the true density of water was presumed to be $1000 \mathrm{~kg} / \mathrm{m}^{3}$, the same as micro-particles of $4000 \mathrm{~kg} / \mathrm{m}^{3}$, and the ratio of amount was calculated for each. Between the ratio of the volume of micro-particles and the optimal granulation moisture, a negative correlation was observed and its gradient was about 1 . According to research by Sekiguchi et al., ${ }^{11)}$ the saturation degree of the pellet formation range is 0.92 to 
1.0, and when APD is used, it is considered that the same voids between particles are in a state occupied by liquid even at a low level of moisture. In other words, under the condition where APD is added, micro-particles are considered to behave as not solid which ingenerates voids but as part of effective liquid which fills in voids, ${ }^{10)}$ and it is presumed that the moisture needed for pelletization can be reduced.

\subsection{Mechanism of Generating Strength during the Drying Process}

Based on the result of observation made using a transmission digital microscope, the rearranging behavior of microparticles is expressed by the pattern diagram in Fig. 13. In the case where APD was added, as drying progresses, the submicron micro-particles in water and the concentration increase of APD continues. As the drying progresses further until reaching complete dryness, hematite particles of
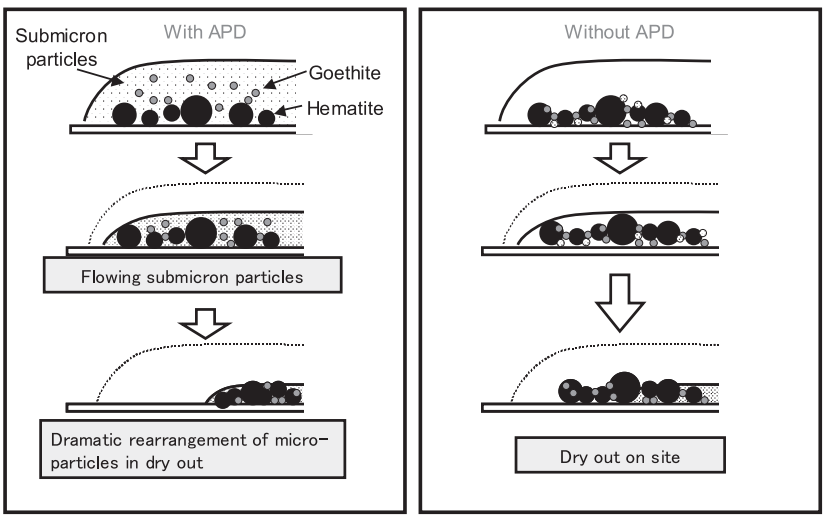

Fig. 13. Schematic of observation result of migration phenomena.

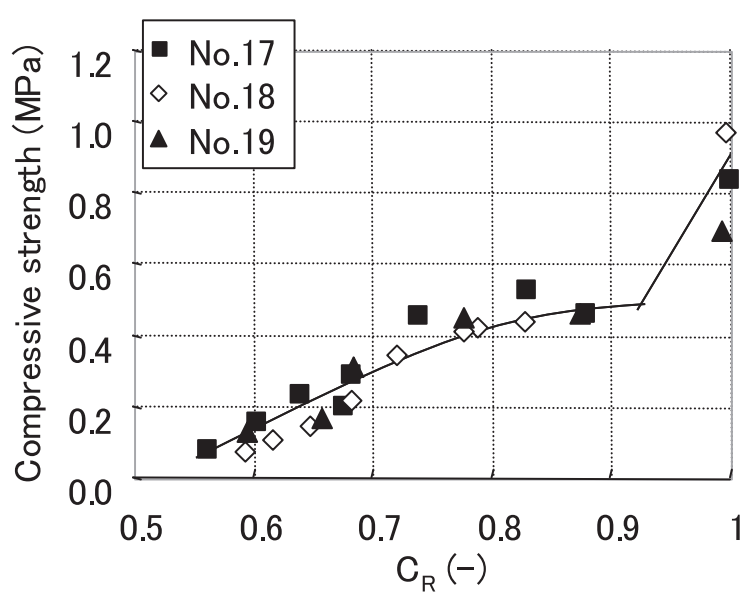

Fig. 14. Relation between compressive strength and micro-particle concentration. around $10 \mu \mathrm{m}$ start moving as if drawn by the movement of the water surface and aggregate, finally forming aggregates and becoming completely dry. As such, the mechanism of rising strength during the drying process needs to be considered in separate phases: the initial drying phase of the micro-particles in water and the increase in APD concentration, and the phase of complete dryness where rearrangement of micro-particles and aggregation take place.

In order to understand the slow rising of strength at the early stage of drying, the concentration of micro-particles is defined as formula (1), and the changes in micro-particle concentration in the granulation moisture was analyzed. The relationship between micro-particles and pellet compressive strength is shown in Fig. 14, which shows that as the microparticle concentration increases, the compressive strength rises. With a micro-particle concentration of 0.5 , the volume ratio of micro-particles to moisture is $2: 8$, and it can be said that micro-particles are drifting in ample water. As the drying progresses and the micro-particle concentration reaches 0.8 , the volume ratio of micro-particles to moisture becomes $1: 1$. This state can be described as one where the microparticles are in a condition of slurry rather than drifting in water. The rise in strength witnessed at this stage can be considered as the process of change from the liquid phase that combines iron ore particles to the viscous state where there are a large number of micro-particles.

When the drying further progresses and reaches dryness just before complete dryness, even comparatively large particles are also considered to move to the joining parts between adhered fine particles, forming hard solid bridges. Therefore, the rise in strength at the early stage of drying is caused by the increase in liquidity viscosity by condensation of micro-particles and APD, and the sudden rise at complete dryness stage can be said to be caused by the formation of solid bridges at the neck portions; the two are explained by fundamentally different mechanisms.

$$
C_{R}=R /\left(R+W_{R}\right)
$$

$C_{R}$ : Concentration of micro-particles in granulation moisture (-)

$R$ : Amount of micro-particles in a raw material (mass $\%$ )

$W_{R}$ : Residual moisture (mass\%)

The behavior image of micro-particles in granules during the drying process prepared based on the above result is shown in Fig. 15. Micro-particles have much to do with the strength of granules in both moist and dry conditions, and the increase in micro-particles is considered to increase the strength not only in a moist condition but also in a dry condition. In other words, by using the dispersant binder, it is possible to improve granule yield and to increase strength

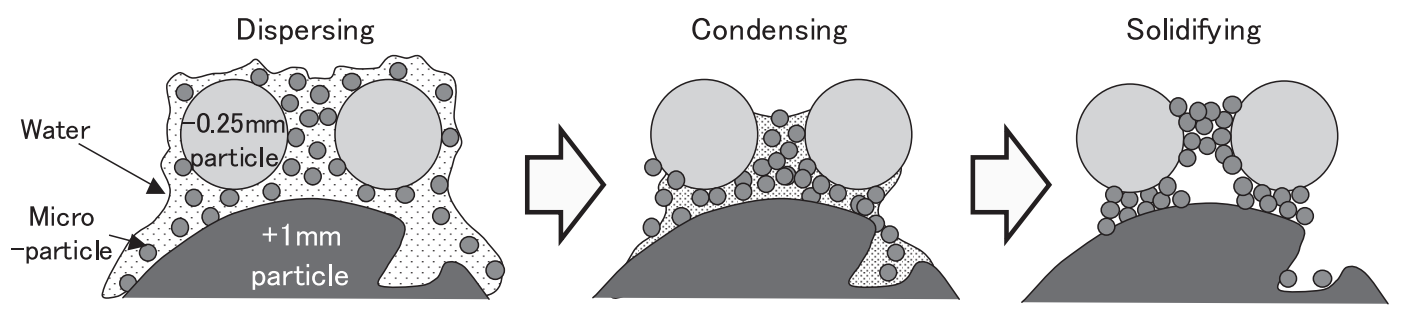

Fig. 15. Migration phenomena of micro-particles in granulation. 
when dried.

\section{Conclusion}

We studied the iron ore granulation mechanism under the existence of a micro-particle dispersant and obtained the following knowledge:

(1) The strength of pellets when completely dried can be explained by the amount of micro-particles in ore, and the greater the amount of micro-particles, the higher the strength of pellets.

(2) The rate of increase in pellet strength by micro-particles when completely dried varies depending on the ore type of micro-particles and the strength increases in the order of pisolite, Marramamba, and hematite.

(3) In the moist condition, since the suspension where micro-particles in dispersion behaves as the liquid, the greater the amount of micro-particles, the less the moisture needed for granulation.

(4) Regarding the generation of pellet strength during the moisture drying process, there are two different mechanisms at work at the early stage and the last stage before complete dryness. The rise in strength at the early stage of drying is considered attributable to the increase in liquid vis- cosity due to the condensation of micro-particles and APD in the liquid, and the increase in strength just before complete dryness is considered attributable to the formation of solid bridges caused by the movement and rearrangement of micro-particles.

(5) By using a dispersant binder in the granulation of iron ore, it is possible to improve the yield and strength of granules when dried.

\section{REFERENCES}

1) T. Haga, A. Ohshio, K. Nakamura, T. Kozono and K. Uekawa: Tetsu-to-Hagané, 83 (1997), 103.

2) N. Ooyama, K. Igawa, K. Takeda, T. Ariyama and T. Jinno: Tetsu-to-Hagané, 90 (2004), 309.

3) T. Okada, J. Okazaki, M. Nakano, K. Kawano and S. Miura: Tetsu-to-Hagané, 92 (2006), 735.

4) T. Inazumi, M. Fujimoto, S. Kasama and K. Sato: Tetsu-to-Hagané, 77 (1991), 63.

5) K. Higuchi, T. Kawaguchi, M. Kobayashi, Y. Hosotani, K. Nakamura, K. Iwamoto and M. Fujimoto: ISIJ Int., 40 (2000), 1188.

6) H. Suzuki, H. Kurokawa, H. Yoshida, S. Kabuto and H. Iida: CAMPISIJ, 8 (1995), 905.

7) T. Kawaguchi and T. Usui: ISIJ Int., 45 (2005), 414.

8) T. Kawaguchi, C. Kamijo and M. Matsumura: Tetsu-to-Hagané, 92 (2006), 779.

9) E. Kasai, S. Komarov, K. Nushiro and M. Nakano: Tetsu-to-Hagané, 92 (2006), 788.

10) S. Kawachi and S. Kasama: ISIJ Int., 49 (2009), 637.

11) I. Sekiguchi and S. Maki: CAMP-ISIJ, 20 (2007), 32. 